\title{
Impact of disablement due to rheumatic disorders in a British population: estimates of severity and prevalence from the Calderdale Rheumatic Disablement Survey
}

\author{
Elizabeth M Badley, Alan Tennant
}

\begin{abstract}
A survey of rheumatic disablement in the population has enabled the comparative impact of self reported causes of disability to be studied. One in three households in Calderdale, West Yorkshire, United Kingdom was screened in 1986 with a postal questionnaire $(87 \%$ response rate), followed by in depth interviews with a sample of subjects reporting disability in conjunction with a rheumatic disorder (608 interviews). Severity of disablement was assessed using the physical independence handicap classification. The estimated prevalence of disability in conjunction with reported rheumatic disorders is $82 / 1000$ population aged at least 16 years (95\% confidence interval (CI) 77 to 87). Arthritis (mainly osteoarthritis) is the most commonly reported cause (47/1000 population; 95\% CI 43 to 51), followed by back or neck disorders $(25 / 1000 ; 95 \%$ CI 23 to 28$)$, soft tissue disorders $(18 / 1000 ; 95 \%$ CI 15 to 20 ), and rheumatoid arthritis (RA) $(4 / 1000 ; 95 \%$ CI 3 to 5 ). A total of $30 \%$ reported more than one category of rheumatic disorder (mean number 1.3 ) and $63 \%$ reported non-rheumatic comorbidity. Current joint symptoms were reported by $98 \%$, current antirheumatic drugs (including analgesics) by $70 \%$, and severe pain by $62 \%$. Overall $82 \%$ of subjects had seen their general practitioner in the past year, and $71 \%$ reported having attended an outpatient clinic; $26 \%$ reported current outpatient clinic attendance, and $15 \%$ a hospital inpatient stay during the previous year. Forty six per cent reported some dependence, with $12 \%$ reporting being dependent on a daily basis. Rheumatoid arthritis was the most disabling disorder with $73 \%$ dependent. Taking into account prevalence, osteoarthritis and back disorders are the most, and RA the least, common causes of dependence and incapacitating pain in the population. This challenges stereotypes and raises questions about the organisation and priorities for specialist services and for research.
\end{abstract}

(Ann Rheum Dis 1993; 52: 6-13)

An impression given by published clinical papers is that rheumatoid arthritis (RA) is the main cause of rheumatic disability. Although it has been consistently found that rheumatic disorders are a major cause of physical disability in the population, ${ }^{1-9}$ less is known about the comparative impact of different types of rheumatic disorder as a cause of disability. Most studies of disability in the community consider the characteristics of the disabled population as a whole. Apart from their mention as a cause of disablement, data on rheumatic disorders are not reported specifically, so there is a lack of information about the nature of rheumatic disablement and the impact on those affected. What little we know of rheumatic disability in the general population is from special analyses for those reporting a rheumatic cause. ${ }^{6-9}$

A survey in which a specific objective was to study the nature of rheumatic disablement in the population was carried out in Calderdale, West Yorkshire, United Kingdom. This paper reports the characteristics of subjects disabled by rheumatic disorders with particular regard to prevalence, severity, and use of medical services.

\section{Methods}

A survey was carried out in 1986 in the population of Calderdale, West Yorkshire, United Kingdom, in which one of the three major objectives was to investigate the nature of rheumatic disablement in the population. ${ }^{10}$ Other major objectives were to gain information to help plan services for those aged 16-64 years who were on the margins of institutional care, and to study the distribution of joint disorders in the population. Calderdale is located in the Pennines in the north of England and had a population of 189402 at the 1981 census. The demographic structure of Calderdale in 1981, with $23 \%$ of its population aged less than 16 years, $61 \%$ aged $16-64,10 \%$ aged $65-74$, and $6 \%$ aged over 75 years, was virtually identical to that of England and Wales at that time, and was relatively stable until the time of the survey.

A two stage methodology was used, similar to that used in other surveys of disablement in the population. ${ }^{11}$ The first stage consisted of postal questionnaires to every third household in the area using the domestic rating list as the sampling frame. The sample size was determined by the need to provide meaningful analysis for a rare group in the population, namely those severely physically disabled aged $16-64$ years based on an estimate of 12 per 10000 people. $^{2}$

The four page screening questionnaire used in phase 1 elicited demographic characteristics of the household, and information about indi- 
viduals within the household who experienced disability in terms of difficulties or dependence in selected activities of daily living. Dependence was defined as requiring help to get in or out of bed, with dressing, to get to and use the toilet, or to get out of the house. An enquiry was made about the nature of the 'main illness or cause of disability'. The questionnaire also asked about subjects in the household who experienced 'joint troubles'-pain, swelling, or stiffness in the joints, neck, or back. For each person with such 'troubles', the site of the affected joint was determined, as well as an indication of the type of joint problem, if known.

Screening questionnaires were sent to 25168 occupied dwellings in Calderdale and 21889 were returned, a response rate of $87 \%$. This was achieved by the original posting (first wave, $57 \%$ response), two further postal follow ups (second and third waves, taking the response to 73 and $81 \%$ respectively), the latter including a small personal call back, and a final postal follow up (the fourth wave).

The second phase sample for the rheumatic disablement survey was drawn from those reporting difficulties or dependence on the phase 1 sift in conjunction with a rheumatic disorder as the main illness or cause of disability. A multistage stratified random sample was drawn with the sampling strata defined by level of disability and age. The overall size of the sample was related to overall cost limitations and the need to obtain a reasonable number of interviews in each stratum. All people identified as dependent in the 16-64 year age group were included in the sample because this group was of particular concern for the survey of younger physically disabled people. The increasing frequency of rheumatic disablement with age meant that sampling fractions were higher for younger age groups-that is, proportionately fewer older people were chosen for interview. It was also considered important to sample adequately those with more severe disability (defined in terms of dependence), a relatively rare occurrence in the population, and not to overwhelm the sample with those with less severe disability, or difficulties in daily living activities. Where more than one person in a household fulfilled the entry criteria only one person was sampled, so that replies to the interview would not be biased by overhearing another's response. There were some instances where it was not clear from the health problems reported on the phase 1 sift whether the cause was a rheumatic disorder or not-for example, 'problems with legs' or 'doesn't walk well'. An additional sample of these query cases was drawn, and cases were reviewed for inclusion after a second stage interview.

The subjects interviewed in each strata represent a proportion of all eligible subjects, and application of these proportions to the phase 2 data can be used to generate an estimate of what the situation would have been if everyone had been interviewed. These estimates are derived from the interview data by a 'weighting' process which takes into account the sampling of households in Calderdale, and the relevant sampling fractions used to select subjects for interview in the second phase. Some adjustments to weights were necessary to allow for non-response at each of the two phases and the exclusions required when more than one eligible person was found in the same household. ${ }^{10}$

Six hundred and ninety six subjects were entered into the rheumatic disablement survey, and successful interviews were obtained with 623 , which represents $90 \%$ of the total sample, and $95 \%$ of those available for interview $(658$ excluding those who had died, moved into institutions, or gone away). The average time between the phase 1 sift and phase 2 interview was three months. Of the 623 interviews, 525 were with those who had reported rheumatic disorders on the sift and 98 with subjects who had a 'query' rheumatic cause.

The interviews were carried out in the respondents' homes by a team of 11 trained interviewers. The interview schedule was about 70 pages long, with 92 key questions giving access to over 600 individual questions. The average interview took about one hour to complete. The range of topics covered most of the major areas of life, including: reported 'health problems and long term complaints'; drugs and use of health and welfare services; household composition and living arrangements, type of housing, and any modifications as a result of disability; use of aids and help in activities of daily living; mobility; employment; leisure activities; and financial situation. Information was also obtained on pain, swelling, or stiffness in the joints, neck, or back, morning stiffness lasting more than 30 minutes, and the presence of severe pain or irritation.

The reported health problems and long term disorders obtained at the phase 2 interview of those 98 subjects reporting a 'query' rheumatic disorder on phase 1 were reviewed. Eighty three subjects were retained in the rheumatic disease sample as having a musculoskeletal disorder.

The self reported health problems were coded as far as possible to International Classification of Diseases (9th revision) terms. ${ }^{12}$ All data were coded twice by different coders and any discrepancies reconciled. The disorders reported were grouped into larger groups as indicated in the appendix. Joint and spinal disorders reported as late effects of trauma were coded to the site of the disorders and included in other joint disorders, and back and neck disorders respectively. In the arthritis group, 81 subjects reported osteoarthritis as a cause. They were not significantly different from the other arthritis group in terms of age, sex, number and site of joints affected, and have therefore been included in the unspecified arthritis group.

Ten cases (unweighted) who reported a rheumatic cause on the sift did not mention a rheumatic cause on interview. In one subject the reported cause on interview was 'had RA, now recovered'. These subjects are included in the overall prevalence estimate for disablement in conjunction with all rheumatic disorders in table 1; the remainder of the results are presented for those with disablement who reported a current rheumatic disorder.

Severity of disablement was assessed using a scale based on the physical independence 
handicap dimension of the World Health Organisation International Classification of Impairments, Disabilities, and Handicaps. ${ }^{13}$ Assessment of the physical independence dimension of handicap is based on the notion of 'interval need' developed by Isaacs and Neville, ${ }^{14}$ and the scale was expanded for analysis of the in depth interviews. ${ }^{15}$ Details of the full scale and its development and application for revision of the physical independence handicap classification are reported elsewhere, as well as information about the validity of estimates by comparison with other measures. ${ }^{15}$ The levels of physical independence considered in this paper are: ( $a$ ) adapted independence-those essentially independent of assistance from others, although difficulty may be experienced; (b) infrequent interval dependence-needs arising no more than once every 24 hours; $(c)$ short interval dependence-needs arising twice daily or every few hours by day, e.g. dependence on others for getting up, dressing and going to bed, and for provision of food and drink or mobility within the home; $(d)$ immediate interval dependence-needs arising at short and unpredictable intervals and requiring the availability of help continuously, or virtually so. This group includes inability to rise from a bed or chair, or walk to and use the toilet, or physical frailty giving rise to potential hazard.

The results are presented as estimates for the whole of Calderdale. Confidence intervals for the weighted data were calculated using the method given in the Super Carp program. ${ }^{16}$ For clarity, confidence intervals (CIs) for estimated percentages are not given in the tables. Estimates where the $\mathrm{CI}$ includes zero are given in parentheses, and those where the confidence interval is $>50 \%$ of the estimated value are shown in italics.
Results

It is estimated that there were 12063 people in Calderdale with disability who reported rheumatic disorders as a cause of their disability or a main health problem, which represents a prevalence of $82 / 1000$ in the population aged 16 years and older (table 1) (95\% CI 77 to 87). The prevalence of disablement in conjunction with rheumatic disorders increases significantly with age (shown by non-overlapping confidence intervals for prevalence estimates) from $4 / 1000$ (95\% CI 3 to 6) in the $16-34$ years age group to $305 / 1000$ (95\% CI 269 to 341 ) in the age group 75 years and older. In this population the prevalence in women $(109 / 1000 ; 95 \%$ CI 101 to $117)$ is twice that in men $(51 / 1000 ; 95 \%$ CI 45 to 57).

Table 1 gives the major rheumatic disorders reported as a cause of health problems or disability. Fifty one per 1000 (95\% CI 46 to 55) of the adult population reported arthritis in conjunction with disability; this includes $4 / 1000$ (95\% CI 3 to 5) reporting $\mathrm{RA}$. The rate of reporting of all the categories increased with age, particularly for unspecified arthritis (mainly, we think, osteoarthritis). There was a decline with age for self reported RA in the 75 years and older age group. This could be a reporting phenomenon whereby people with RA reported unspecified arthritis. It could also be linked with a lower referral rate to specialists among the elderly in this group, ${ }^{17}{ }^{18}$ and reflect that older people are less likely to have been given a clear diagnosis.

The prevalence of reported back or neck disorders in conjunction with disability was $25 / 1000$ (95\% CI 23 to 28 ) and 18/1000 (95\% CI 15 to 20) for soft tissue disorders, and there was a moderate increase in prevalence with age. The mean age of those reporting disablement and

Table 1 Rates of disablement in those with self reported rheumatic disorders by type of rheumatic disorders, age, and sex. Estimated number and rate per 1000 population with $95 \%$ confidence intervals. Estimated confidence interval (CI) of estimates in parentheses includes 0; italics indicate the confidence interval is $>50 \%$ of the estimated value

\begin{tabular}{|c|c|c|c|c|c|c|c|c|c|}
\hline $\begin{array}{l}\text { Rheumatic } \\
\text { disorder }\end{array}$ & & $\begin{array}{l}\text { All } \\
\text { ages }\end{array}$ & Men & Women & $\begin{array}{l}16-34 \\
\text { years }\end{array}$ & $\begin{array}{l}35-54 \\
\text { years }\end{array}$ & $\begin{array}{l}55-64 \\
\text { years }\end{array}$ & $\begin{array}{l}65-74 \\
\text { years }\end{array}$ & $\begin{array}{l}75+ \\
\text { years }\end{array}$ \\
\hline $\begin{array}{l}\text { All rheumatic } \\
\text { disorders } \\
\text { Arthritis } \\
\text { Unspecified } \\
\text { Rheumatoid } \\
\text { arthritis } \\
\text { Back or } \\
\text { neck } \\
\text { Soft tissue } \\
\text { Other joint }\end{array}$ & $\begin{array}{l}\text { Estimated No } \\
\text { Rate } \\
( \pm 95 \% \text { CI) } \\
\text { Estimated No } \\
\text { Rate } \\
( \pm 95 \% \text { CI }) \\
\text { Estimated No } \\
\text { Rate } \\
( \pm 95 \% \text { CI }) \\
\text { Estimated No } \\
\text { Rate } \\
\text { ( } \pm 95 \% \text { CI }) \\
\text { Estimated No } \\
\text { Rate } \\
\text { ( } \pm 95 \% \text { CI) } \\
\text { Estimated No } \\
\text { Rate } \\
\text { ( } \pm 95 \% \text { CI })\end{array}$ & $\begin{array}{c}12063 \\
81 \cdot 6 \\
5 \cdot 1 \\
6899 \\
46 \cdot 7 \\
3 \cdot 9 \\
639 \\
4 \cdot 3 \\
1 \cdot 1 \\
3750 \\
25 \cdot 4 \\
2 \cdot 7 \\
2590 \\
17 \cdot 5 \\
2 \cdot 2 \\
2097 \\
14 \cdot 2 \\
1.9\end{array}$ & $\begin{array}{c}3571 \\
51 \cdot 2 \\
6.0 \\
1673 \\
24 \cdot 0 \\
4 \cdot 0 \\
122 \\
1.8 \\
0.6 \\
1102 \\
15 \cdot 8 \\
3.2 \\
675 \\
9 \cdot 7 \\
2.6 \\
939 \\
13.5 \\
2.0\end{array}$ & $\begin{array}{c}8492 \\
108 \cdot 7 \\
8.0 \\
5227 \\
66.9 \\
6.5 \\
517 \\
6.6 \\
1.8 \\
2648 \\
33 \cdot 9 \\
4 \cdot 2 \\
1915 \\
24 \cdot 5 \\
3.5 \\
1158 \\
14 \cdot 8 \\
2.5\end{array}$ & $\begin{array}{c}225 \\
4.4 \\
1.7 \\
40 \\
0.8 \\
0.5 \\
(14) \\
(0 \cdot 3) \\
(0 \cdot 3) \\
114 \\
2.2 \\
1.0 \\
104 \\
2.0 \\
0.7 \\
31 \\
0.6 \\
0.4\end{array}$ & $\begin{array}{c}2355 \\
50 \cdot 9 \\
5 \cdot 2 \\
815 \\
17 \cdot 6 \\
3 \cdot 0 \\
107 \\
2 \cdot 3 \\
0 \cdot 8 \\
973 \\
21 \cdot 0 \\
3 \cdot 4 \\
569 \\
12 \cdot 3 \\
2 \cdot 3 \\
549 \\
11 \cdot 9 \\
2 \cdot 4\end{array}$ & $\begin{array}{c}2595 \\
123 \cdot 8 \\
12 \cdot 8 \\
1586 \\
75 \cdot 6 \\
9 \cdot 6 \\
176 \\
8 \cdot 4 \\
3 \cdot 2 \\
964 \\
46 \cdot 0 \\
7 \cdot 6 \\
527 \\
25 \cdot 1 \\
5 \cdot 4 \\
362 \\
17 \cdot 3 \\
4 \cdot 7\end{array}$ & $\begin{array}{c}3129 \\
184 \cdot 3 \\
24 \cdot 6 \\
2047 \\
120 \cdot 6 \\
19 \cdot 7 \\
228 \\
13 \cdot 4 \\
6 \cdot 7 \\
911 \\
53 \cdot 7 \\
12 \cdot 3 \\
482 \\
28 \cdot 4 \\
9 \cdot 1 \\
689 \\
40 \cdot 6 \\
10 \cdot 7\end{array}$ & $\begin{array}{c}3759 \\
304 \cdot 7 \\
35 \cdot 8 \\
2412 \\
195 \cdot 5 \\
29 \cdot 8 \\
115 \\
9 \cdot 3 \\
4 \cdot 9 \\
788 \\
63 \cdot 9 \\
17 \cdot 3 \\
908 \\
73 \cdot 6 \\
16 \cdot 3 \\
466 \\
37 \cdot 8 \\
9 \cdot 4\end{array}$ \\
\hline
\end{tabular}

Table 2 Morbidity and joint symptoms in those with disablement and rheumatic disorders

\begin{tabular}{|c|c|c|c|c|c|}
\hline Rheumatic disorder & Estimated No & $\begin{array}{l}\text { Percentage with } \\
\text { one rheumatic } \\
\text { disorder only }\end{array}$ & $\begin{array}{l}\text { Percentage with } \\
\text { current joint } \\
\text { symptoms }\end{array}$ & $\begin{array}{l}\text { Percentage } \\
\text { reporting } \\
\text { current drugs }\end{array}$ & $\begin{array}{l}\text { Percentage with } \\
\text { moming stiffness } \\
>30 \text { minutes }\end{array}$ \\
\hline $\begin{array}{l}\text { All rheumatic disorders } \\
\text { Arthritis }\end{array}$ & 11905 & $70 \cdot 2$ & $97 \cdot 5$ & $70 \cdot 1$ & $36 \cdot 8$ \\
\hline $\begin{array}{l}\text { Unspecified } \\
\text { Rheumatoid arthritis } \\
\text { Back or neck } \\
\text { Soft tissue } \\
\text { Other joint }\end{array}$ & $\begin{array}{r}6899 \\
639 \\
3750 \\
2590 \\
2097\end{array}$ & $\begin{array}{l}65 \cdot 3 \\
86 \cdot 7 \\
37 \cdot 6 \\
37 \cdot 7 \\
43 \cdot 7\end{array}$ & $\begin{array}{l}98 \cdot 2 \\
97 \cdot 5 \\
98 \cdot 9 \\
96 \cdot 1 \\
95 \cdot 3\end{array}$ & $\begin{array}{l}75 \cdot 4 \\
89 \cdot 3 \\
75 \cdot 2 \\
59 \cdot 8 \\
46 \cdot 8\end{array}$ & $\begin{array}{l}33 \cdot 8 \\
47 \cdot 8 \\
38 \cdot 2 \\
31 \cdot 1 \\
34 \cdot 7\end{array}$ \\
\hline
\end{tabular}


rheumatic disorders was 66 years $(95 \%$ CI 65 to 67). This did not differ significantly between the major categories of reported rheumatic disorder (data not shown). For all conditions except for the other joint disorder category there was a significantly higher population prevalence in women than men.

The prevalence rates for the different types of rheumatic disorder add up to more than the overall rate as some respondents reported more than one category of rheumatic disorder. The mean number of categories of rheumatic disorder reported was $1 \cdot 3 ; 70 \%$ reporting one category of rheumatic disorder only (table 2). Arthritis, particularly RA, was more likely to be reported as the sole rheumatic disorder. Less than half of those reporting back or neck, soft tissue, or other joint disorders reported one rheumatic disorder only. Major combinations in the $\mathbf{3 5 1 0}$ estimated subjects with rheumatic comorbidity were arthritis and back disorders (32\% of all combinations), back and soft tissue (17\%), arthritis and soft tissue (14\%), arthritis and other joint disorders (12\%); other combinations accounted for less than $7 \%$ of the total.

In addition to a rheumatic cause of disability $63 \%$ reported other (non-rheumatic) health problems. The most frequently reported comorbid conditions were heart disease, digestive, respiratory, and sensory disorders, reflecting their high prevalence in the population, ${ }^{19}$ and in the case of digestive disorders perhaps the side effects of antirheumatic drugs. ${ }^{20}$

Most respondents reported current joint symptoms (pain, swelling, or stiffness in the joints, neck, or back) (table 2). The mean number of troublesome joints, out of the 18 sites for which information was asked, was 6.3 (95\% CI 6.0 to 6.6). Means for the rheumatic disease subgroups were not significantly different, except for RA (mean $11 \cdot 1$; $95 \%$ CI $9 \cdot 6$ to $12 \cdot 6$ ), which was higher, and other joint disorders (mean $4 \cdot 7 ; 95 \%$ CI $4 \cdot 0$ to $5 \cdot 3$ ), which was lower. Current antirheumatic drugs, including use of analgesics, was reported by
$70 \%$; once again the proportion was higher for those with RA. The proportion reporting morning stiffness of more than 30 minutes' duration was $37 \%$ and there was no significant difference between the diagnostic subgroups.

The pain associated with rheumatic disorders had an appreciable effect on daily life. Over $60 \%$ reported severe pain and irritation in response to a general question (table 3). Of these $\mathbf{4 5 \%}$ said the pain limited daily activities, $37 \%$ reporting that the ability to lead a normal life was affected; $22 \%$ said they were always in pain. When the different types of rheumatic disorder are compared the proportions are highest for those with RA, with half reporting that they were always in pain.

Table 4 gives an indication of the overall use of medical services. There was some variation in the pattern of use between the rheumatic disorders. ${ }^{79}$ Eighty per cent of respondents with disablement in association with rheumatic disorders had seen their general practitioner in the past year. The percentage was slightly higher for those reporting RA. The proportion reporting attending or having attended an outpatient clinic was also high (70\% overall, and $80 \%$ for those with RA), though, however, only about $25 \%$ reported current outpatient clinic attendance. These data refer to any specialty and not just those relevant to these disorders such as rheumatology and orthopaedics. Only $15 \%$ had a hospital inpatient stay during the previous year; this was similar for all rheumatic disorder categories.

Table 5 shows the level of physical independence handicap. Just under a half of people with disablement reported some level of dependence, with one in eight overall reporting being dependent on a daily basis (short interval dependence or greater). Rheumatoid arthritis was the most disabling condition; $73 \%$ were dependent, with $30 \%$ reporting short or immediate interval need.

The overall prevalence of dependence in conjunction with the different categories of

Table 3 Frequency of reported severe pain or irritation, or both, and its impact in those with disablement and rheumatic disorders

\begin{tabular}{|c|c|c|c|c|c|}
\hline \multirow[t]{2}{*}{ Rheumatic disorder } & \multirow[t]{2}{*}{ Estimated No } & \multicolumn{4}{|c|}{ Percentage with severe pain or irritation, or both } \\
\hline & & Total & $\begin{array}{l}\text { Limits daily } \\
\text { activities }\end{array}$ & $\begin{array}{l}\text { Affects ability } \\
\text { to lead } \\
\text { normal life }\end{array}$ & $\begin{array}{l}\text { Always in } \\
\text { pain }\end{array}$ \\
\hline $\begin{array}{l}\text { All rheumatic disorders } \\
\text { Arthritis }\end{array}$ & 11905 & 61.6 & $45 \cdot 4$ & $37 \cdot 2$ & $21 \cdot 7$ \\
\hline $\begin{array}{l}\text { Unspecified } \\
\text { Rheumatoid arthritis } \\
\text { Back or neck } \\
\text { Soft tissue } \\
\text { Other joint }\end{array}$ & $\begin{array}{r}6899 \\
639 \\
3750 \\
2590 \\
2097\end{array}$ & $\begin{array}{l}66 \cdot 0 \\
82 \cdot 5 \\
63 \cdot 4 \\
52 \cdot 5 \\
43 \cdot 1\end{array}$ & $\begin{array}{l}48 \cdot 8 \\
66 \cdot 7 \\
46 \cdot 8 \\
37 \cdot 0 \\
30 \cdot 0\end{array}$ & $\begin{array}{l}41 \cdot 0 \\
59 \cdot 6 \\
39 \cdot 9 \\
27 \cdot 2 \\
24 \cdot 7\end{array}$ & $\begin{array}{l}23 \cdot 2 \\
50 \cdot 7 \\
19 \cdot 5 \\
14 \cdot 8 \\
14 \cdot 4\end{array}$ \\
\hline
\end{tabular}

Table 4 Use of medical services and drugs by those with disablement and rheumatic disorders

\begin{tabular}{|c|c|c|c|c|c|}
\hline Rheumatic disorder & Estimated No & $\begin{array}{l}\text { Percentage seeing } \\
\text { general practitioner } \\
\text { in past year }\end{array}$ & $\begin{array}{l}\text { Percentage } \\
\text { attended out- } \\
\text { patient clinic }\end{array}$ & $\begin{array}{l}\text { Percentage currently } \\
\text { attending out- } \\
\text { patient clinic }\end{array}$ & $\begin{array}{l}\text { Percentage inpatient } \\
\text { in past year }\end{array}$ \\
\hline $\begin{array}{l}\text { All rheumatic disorders } \\
\text { Arthritis }\end{array}$ & 11905 & $82 \cdot 1$ & $70 \cdot 5$ & $25 \cdot 8$ & $14 \cdot 7$ \\
\hline $\begin{array}{l}\text { Unspecified } \\
\text { Rheumatoid arthritis } \\
\text { Back or neck } \\
\text { Soft tissue } \\
\text { Other joint }\end{array}$ & $\begin{array}{r}6899 \\
639 \\
3750 \\
2590 \\
2097\end{array}$ & $\begin{array}{l}81 \cdot 5 \\
88 \cdot 9 \\
81 \cdot 6 \\
82 \cdot 0 \\
78 \cdot 4\end{array}$ & $\begin{array}{l}71 \cdot 6 \\
80 \cdot 4 \\
75 \cdot 4 \\
66 \cdot 4 \\
64 \cdot 9\end{array}$ & $\begin{array}{l}28 \cdot 2 \\
34 \cdot 9 \\
24 \cdot 4 \\
17 \cdot 3 \\
26 \cdot 5\end{array}$ & $\begin{array}{r}17 \cdot 1 \\
15 \cdot 4 \\
15 \cdot 4 \\
7 \cdot 9 \\
15 \cdot 6\end{array}$ \\
\hline
\end{tabular}


Table 5 Physical independence handicap in those with disablement and rheumatic disorders. Italics indicate the confidence interval is $>50 \%$ of the estimated value

\begin{tabular}{|c|c|c|c|c|c|}
\hline \multirow[t]{2}{*}{ Rheumatic disorders } & \multirow[t]{2}{*}{ Estimated No } & \multirow{2}{*}{$\begin{array}{l}\text { Adapted indepen- } \\
\text { dence }(\%)\end{array}$} & \multicolumn{3}{|c|}{ Dependence (\%) } \\
\hline & & & $\begin{array}{l}\text { Infrequent } \\
\text { interval }\end{array}$ & $\begin{array}{l}\text { Short } \\
\text { interval }\end{array}$ & $\begin{array}{l}\text { Immediate } \\
\text { interval }\end{array}$ \\
\hline $\begin{array}{l}\text { All rheumatic disorders } \\
\text { Arthritis }\end{array}$ & 11905 & $54 \cdot 5$ & $33 \cdot 1$ & $9 \cdot 8$ & $2 \cdot 6$ \\
\hline $\begin{array}{l}\text { Unspecified } \\
\text { Rheumatoid arthritis } \\
\text { Back or neck } \\
\text { Soft tissue } \\
\text { Other joint }\end{array}$ & $\begin{array}{r}6899 \\
639 \\
3750 \\
2590 \\
2097\end{array}$ & $\begin{array}{l}52 \cdot 9 \\
26 \cdot 8 \\
58 \cdot 6 \\
59 \cdot 1 \\
69 \cdot 3\end{array}$ & $\begin{array}{l}33 \cdot 4 \\
42 \cdot 8 \\
32 \cdot 5 \\
33 \cdot 8 \\
20 \cdot 2\end{array}$ & $\begin{array}{r}10 \cdot 7 \\
20 \cdot 4 \\
7 \cdot 1 \\
5 \cdot 5 \\
8 \cdot 0\end{array}$ & $\begin{array}{r}3 \cdot 0 \\
10 \cdot 0 \\
1 \cdot 8 \\
1 \cdot 5 \\
2 \cdot 5\end{array}$ \\
\hline
\end{tabular}

rheumatic disorder is illustrated in the figure where the disorders are given in decreasing magnitude of rate of dependence; this is also the same order as the prevalence of these conditions in association with any level of disablement. The most common cause is unspecified arthritis followed by back or neck disorders. A relative ranking of rheumatic disorders can be obtained for severe pain by applying the percentages in table 3 to the prevalence estimates. Even though RA is the most severely disabling in terms of the proportion who are dependent and results in a higher proportion of subjects with incapacitating pain, because of its relative infrequency in the population this does not affect its relative ranking as a reason for disablement in the population.

\section{Discussion}

The overall rate of disablement in association with rheumatic disorders found in this survey was $8 \cdot 2 \%$ of the population aged 16 years and older. This estimate is of the same order of magnitude as that found in other surveys, ${ }^{14-9}$ though it is difficult to compare exactly estimates from different surveys because of the impact of different definitions and methods of ascertain-

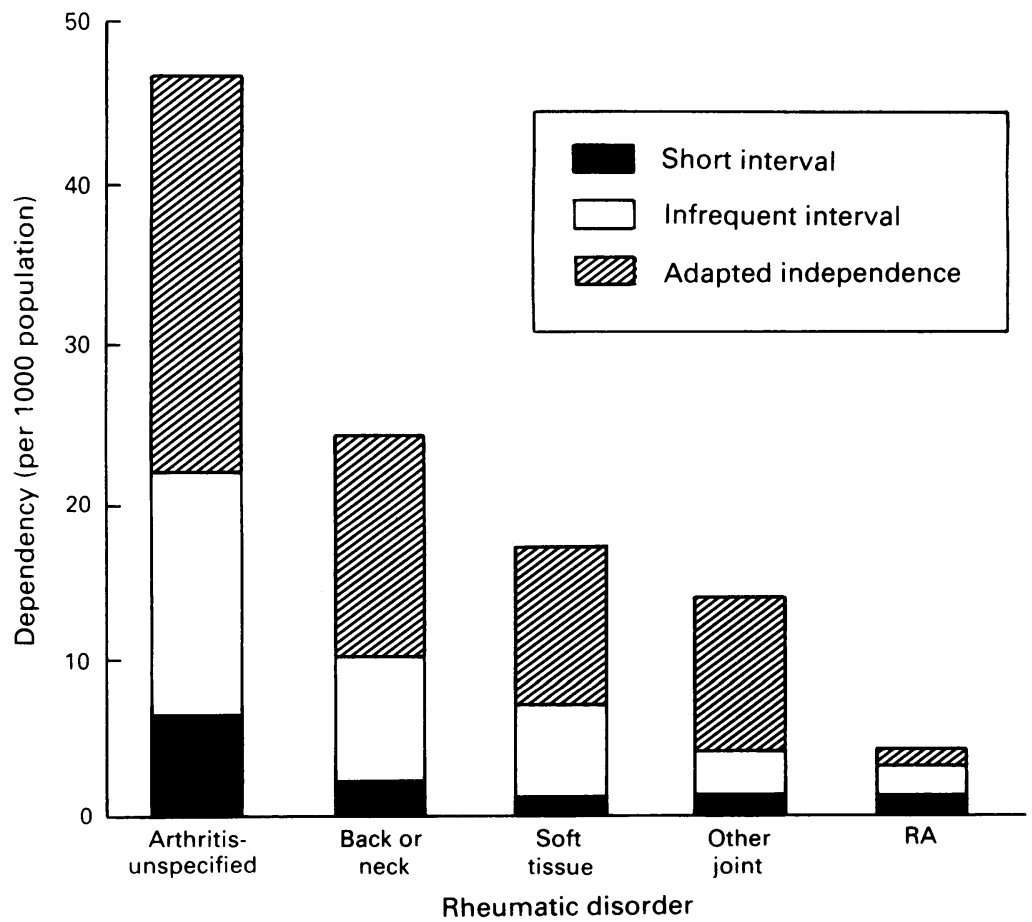

Population prevalence of physical independence handicap in those with disablement and selected rheumatic disorders. $R A=$ rheumatoid arthritis. ment of disability. We also found that disable ment was more common in women and with increasing age. ${ }^{13192122}$ The 1986 government survey of disability in Great Britain suggests that for adults living in private households the prevalence of disability due to disorders attributable to the musculoskeletal system is $6 \cdot 2 \%$. The higher prevalence in the current survey may reflect the fact that our screening questionnaire was made more sensitive to disability associated with the rheumatic diseases by including activities such as combing and brushing hair, doing up buttons and zips, and getting out of a low chair. It also asked about difficulty putting on shoes, socks, or stockings (an activity causing difficulty for those with back disorders $^{23}$ )

The North American approach to ascertainment of disablement in surveys has been to concentrate on activity restriction. Reported data from the HANES1 survey allows an estimation that $6.3 \%$ of the population in the 24-75 age group have joint symptoms and moderate to severe activity restriction. ${ }^{21}$ This can be compared with a rate of $6.1 \%$ in this survey for the age range 16-74 years. Analysis of the US Health Interview Survey suggests that musculoskeletal impairments affect about $10 \%$ of the population, and that impairments due to the back or spine are almost half of these. ${ }^{4}$ Overall the reported prevalence of disability caused by musculoskeletal disorders was $7 \%$ in the Canadian Health and Disability Survey. ${ }^{24}$ Here disability was defined in terms of problems lasting more than six months which gave rise to trouble in performing any one of 17 activities (such as going up and down stairs) or limitation in the amount of activity at home, work, or school. ${ }^{24}$ The prevalence of rheumatic disorders in the Swedish population aged 16-74 years which are a cause of long term illness, any handicap, or other debility is of the order of $12-13 \%$, and increases markedly with age. ${ }^{22}$ No indication is given of the proportion of those who have disabilities.

A much lower prevalence estimate of 3\% was found in the earlier survey of handicap and disability in Great Britain (the Harris survey). ${ }^{236}$ The Harris survey screening questions, however, were more directed to need for personal assistance and to be looked after. A more appropriate comparison would be with the prevalence of $3.7 \%$ found in our survey for those with dependence according to the physical independence handicap measure. ${ }^{15}$

The prevalence of $8 \cdot 2 \%$ found in the phase 2 interview of this survey falls between the 
estimates from the phase 1 postal sift of $7 \cdot 2 \%$ (95\% CI $7 \cdot 0$ to $7 \cdot 5$ ) where rheumatic disorders were specifically mentioned as a cause of disability on the household postal questionnaire, and of $9.6 \%(95 \%$ CI $9 \cdot 3$ to $9 \cdot 9)$, for the prevalence of disablement in association with joint troubles (pain, swelling, or stiffness in the joints, neck, or back). ${ }^{17}$ It is likely that ascertainment of the presence of rheumatic disorders was better in the face to face interview than in the postal questionnaire where reporting of information might have been subject to a proxy effect, as the questionnaire could be completed by one household member on behalf of all others. ${ }^{25}$

Comparison between surveys of the relative contribution of different types of rheumatic disability is problematic due to differences in coding and methods of ascertainment. In our survey arthritis was mentioned by $63 \%$ of those reporting rheumatic disorders, highlighting the dominance of arthritis as a cause of rheumatic disability; this is in line with other surveys. For every subject reporting RA there were about 10 who reported other arthritis. This ratio is similar to that found in the US National Health Interview survey reports of selected chronic conditions as a cause of activity limitation $(2 \cdot 8$ and 23.7 per 1000 total population. ${ }^{19}$ The ratio found in the British government survey was slightly higher $(5.4$ and 36.4 per 1000 household population aged 16 years and older). ${ }^{1}$ We have already indicated that we suspect that some subjects with RA might have reported unspecified arthritis. We found a prevalence of reported back or neck disorders of $2 \cdot 4 \%$. This is higher than that found in the British government survey but consistent with the figure of $2 \cdot 1 \%$ of the total population for the back related chronic conditions and impairments covered in the US Health Interview Survey. ${ }^{19}$

This survey was designed to look specifically at the nature of rheumatic disability in adults. The study sample excluded children, and also adults aged 65 years and older who reported a non-rheumatic cause of disability.

Problems arise with the attribution of a specific rheumatic disorder as the cause of disablement. The level of comorbidity was high in terms of the coexistence of more than one type of rheumatic disorder and of rheumatic with other types of disorder. The latter means that it is not possible to compare the relative magnitude of disablement due to rheumatic disorders with that from other conditions. This means that we cannot say the disability experienced resulted directly from the rheumatic disorder. We feel that to force respondents to specify the main cause of a disability is an artificial situation, and the course taken in this survey is more likely to reflect the nature of disability experience in the general population.

The information on the nature of health problems was collected by self reporting. Work on the accuracy of self reported disorders in surveys of disability of the population has shown them to be acceptably accurate, at least in terms of the main types of condition reported. ${ }^{26}$ We carried out a validation exercise whereby patients attending an outpatients clinic were asked to complete the phase 1 screening questionnaire. We found a high degree of accuracy for reports of arthropathies, although this was less so for disorders affecting the soft and connective tissues. ${ }^{27}$

Most respondents reported current joint symptoms (pain, swelling, or stiffness in the joints, neck, or back) but only $62 \%$ reported having severe pain and irritation. This could be an indication of the severity of the joint symptoms, though other work has indicated that measures of overall pain may not necessarily reflect pain in individual joints. ${ }^{28}$ Most were currently taking some form of relevant drugs, including non-steroidal anti-inflammatory drugs (NSAIDs) as well as analgesics, indicating the presence of symptoms. It is noteworthy that the proportion of those with back, neck, or soft tissue disorders reporting severe pain was similar to that for arthritis. The impact of pain on daily activities and the ability to lead a normal life for those with spinal disorders and arthritis were also comparable.

The proportion reporting morning stiffness lasting more than $\mathbf{3 0}$ minutes is lower than that found in earlier population surveys. ${ }^{29}$ It is also lower than the figure of $50 \%$ reported by subjects with rheumatic disorders in the phase 1 postal questionnaire. ${ }^{17}$ The findings from the phase 2 interview could well be a reflection of the placing of the question in the interview schedule. It immediately followed questions on individual joints and could well have been interpreted as referring specifically to joint stiffness.

Our data on the use of services refer to those with rheumatic disorders who have disabilities. Thus they relate to the subset of the total number of people with these disorders who are more seriously affected, at least in terms of functional status. The high proportion seeing their general practitioner in the course of a year underlines the key role of the general practitioner in the long term management of these chronic disorders. It is nevertheless disturbing that $20 \%$ apparently had no contact in the last year, though the magnitude of any under reporting cannot be gauged. Similar results were found for outpatient clinic attendance. Only about a quarter reported current outpatient clinic attendance (to any type of outpatient clinic). Even if there were substantial under reporting on this item, the implication is that for many there is no ongoing specialist intervention in the management of their disorder. The low rate of consultation may reflect the fact that the level of service provision in rheumatology in Calderdale was only $39 \%$ of the optimum input for the United Kingdom. ${ }^{30}$ This might affect the rate of referral to specialists by general practitioners, and, if patients have to travel some distance to see a rheumatologist, then their ability to do so may decline with increasing disablement. These figures did not refer to rheumatology specifically; patients could have been referred to other specialties. Data on inpatient admission for RA, however, shows that the rate of admission to any specialty is lower in districts without rheumatological input. ${ }^{31}$ 
The survey highlights the effect of disablement in association with rheumatic disorders on the population. There is a pronounced age related increase in the reporting of disablement in those with rheumatic disorders. This has been found in other studies of rheumatic disablement in the population. ${ }^{1319}$ The increase with age of those reporting disablement, particularly dependence, and rheumatic disorders is of concern in the context of the ageing population. The proportion of those aged 65 years and older in the population of the United Kingdom is expected to increase by a quarter from $15 \%$ in 1985 to $21 \%$ by $2030 .{ }^{32} 33$ The older age groups contain a disproportionate number of women and the prevalence of rheumatic disablement is also higher in women. As the proportion of older people in the population increases this will have implications for the provision of care in community and hospital settings. The increasing prevalence of disablement in terms of dependence is of special concern as a large proportion of those who are 65 years and older live alone; at the time of the United Kingdom 1981 census almost a third of older people lived alone and almost half lived with a spouse only. ${ }^{34}$ The relatively low figures for contact with medical services also raise questions about whether these people have ever had adequate intervention from the health care system which might modify or postpone the onset of disablement.

Of the rheumatic disorders considered here, as might be expected, subjects with RA had more severe disability as reflected by level of dependence on others. They also had more current symptoms and made more use of medical services. This is put into perspective, however, when the prevalence of the different types of rheumatic disorders is considered. Although only $14 \%$ of those with unspecified arthritis have short or immediate needs dependence, because of its much higher prevalence it is a more frequent cause of dependence in the population than RA where over $30 \%$ have this level of dependence (figure). Similarly spinal and soft tissue disorders are more often a cause of dependence than RA. Analogous reasoning can be applied to the effect of severe pain and to the use of medical services for these disorders. Most attendances in general practice and at outpatient clinics would be subjects with disablement and rheumatic disorders other than RA. ${ }^{7}$

Simultaneous consideration of severity and prevalence produces a picture of dependence and pain where unspecified arthritis and back or neck disorders dominate for those with rheumatic causes of disablement. The fact that osteoarthritis and back disorders are the most common causes of rheumatic disablement in the population challenges stereotypes. This raises questions about the nature, organisation, and priorities for specialist services and for research.

This work was supported by the Arthritis and Rheumatism Council. Particular acknowledgement is due to the staff of the ARC epidemiology unit, University of Manchester, United Kingdom who contributed to the conduct of the survey and the data management, processing, and analysis, and to the unit's director Professor Philip H N Wood for overall guidance and director Professor Philip H N Wood for overall guidance and this paper and Dominique Ibanez for statistical advice.
1 Martin J, White A. The prevalence of disability among adults. OPCS surveys of disability in Great Britain. Report 1 . OPCS Social Survey Division, London: HMSO, 1988.

2 Harris A I. Handicapped and impaired in Great Britain, Part 1. OPCS, London: HMSO, 1971.

3 Badley E M, Thompson R P, Wood P H N. The prevalence and severity of major disabling conditions - a reappraisal of the government social survey of the handicapped and impaired in Great Britain. Int $\mathcal{F}$ Epidemiol 1978; 7: 145-51.

4 Kelsey J L. Epidemiology of musculoskeletal disorders. New York: Oxford University Press, 1982.

5 Health and Welfare Canada, Statistics Canada. The Health of Canadians. Report of the Canada Health Survey. Ottawa: Ministry of Supply and Services, 1981.

6 Wood P H N, Badley E M. Epidemiology of locomoto disorders in general practice. In: Jayson M I V, Million R, eds. Locomotor disability in general practice. Oxford: Oxford eds. Locomotor disability in general

7 Wood P H N, Badley E M. Epidemiology of individual rheumatic disorders. In: Scott J T, ed. Copeman's textbook of rheumatic diseases. 6th ed. London: Churchill Livingstone, 1986: 59-142.

8 Felts W, Yelin E. The economic impact of the rheumatic diseases in the United States. $\mathcal{F}$ Rheumatol 1989; 16 867-84.

9 Kramer J S, Yelin E H, Epstein W V. Social and economic impacts of four musculoskeletal conditions. A study using national community-based data. Arthritis Rheum 1983; 26: 901-7.

10 Badley E M, Tennant A. Calderdale health and disablement survey. Manchester: Arthritis and Rheumatism Council for Research, 1988.

11 Harris A I, Head E. Sample surveys in local authority areas London: OPCS, 1971

12 World Health Organisation. International Classification of Diseases, 9th rev. Geneva: World Health Organisation, 1979.

13 World Health Organisation. The International classification of impairments, disabilities, and handicaps. Geneva: World impairments, disabilities, and

14 Isaacs $\mathrm{B}$, Neville $\mathrm{Y}$. The measurement of need in old people. Edinburgh: HMSO, 1976. (Scottish Health Service Studie No 34.)

15 Badley E M, Tennant A, Wood P H N. The assessment of physical independence handicap: experience in a com munity disablement survey. Int Disabil Stud 1990; 12 47-53.

16 Hidiroglou M A, Fuller W A, Hickman R D. Super Carp program. 6th ed. Survey Section Statistical Library, Iowa program. 6th ed. Survey

17 Badley E M, Tennant A. Changing profile of joint disorders with age: findings from a postal survey of the population of Calderdale, West Yorkshire, United Kingdom. Ann Rheum Dis 1992; 51: 366-71.

18 Tennant A, Badley E M. Rheumatic disablement and the use of medical services. London: Arthritis and Rheumatism Council, 1990.

19 LaPlante M. Data on disability from the National Health Interview Survey, 1983-85. An InfoUse Report. Washington, Interview Survey, 1983-85. An InfoUse Report. Washington, DC: US National

20 Hawkey C J. Non-steroidal anti-inflammatory drugs and peptic ulcers. $B M \mathcal{F} 1990$; 300: 278-84

21 Cunningham L S, Kelsey J L. Epidemiology of musculoskeletal impairments and associated disability. Am $\mathcal{Y}$ Public Health 1984; 74: 574-9.

22 Bjelle A, Allander E, Magi M. Rheumatic disorders in the Swedish population and health care system. 7 Rheumatol 1980; 7: 877-85.

23 Wood P H N, Badley E M. Back pain in the community. In: Grahame R, ed. Clinics in rheumatic diseases Vol. 6 London: Saunders, 1980: 3-16.

24 Statistics Canada, Department of the Secretary of State of Canada. Report of the Canadian health and disability survey 1983-1984. Ottawa: Ministry of Supply and Services Canada, 1986.

25 Tennant A, Badley E M, Sullivan M. Investigating the proxy effect and the saliency principle in household based posta questionnaires. $\mathcal{F}$ Epidemiol Community Health 1991; 45, 312-6.

26 Warren M D. Interview surveys of handicapped people: the accuracy of statements about the underlying medical conditions. Rheumatol Rehabil 1976; 15: 202-9.

27 Papageorgiou A C, Wood P H N, Badley E M. Comparison of clinical and self-reported diagnosis for rheumatology outpatients [abstract]. Br $\mathcal{Z}$ Rheumatol 1989; 28 (suppl 1): 32.

28 Badley E M, Papageorgiou A C. Visual analog scales to measure pain in arthritis: a study of overall pain and pain in individual joints at rest and on movement. $\mathcal{f}$ Rheumato 1989; 16: 102-5

29 Lawrence I S. Rheumatism in populations. London: Heinemann, 1977.

30 Wood P H N. For the want of a horse. Br $\mathcal{X}$ Rheumatol 1986; 25: $235-42$.

31 Badley E M. Evaluating the consequences of new consultan appointments in rheumatology in the NW region. $B r f$ Rheumatol 1985; 24: $210-1$.

32 Thompson J. Ageing of the population; contemporary trends and issues. Population Trends 1988; 21: 18-22.

33 Badley $E$ M. Population projections and the effect on rheumatology. Ann Rheum Dis 1991; 50: 3-6.

34 Family Policies Studies Centre. Fact Sheet. An ageing population. London: Family Policies Studies Centre, 1984. 
Appendix Groupings of reported rheumatic disorder categories with associated International Classification of Diseases (9th revision) cddes $^{12}$

\begin{tabular}{ll}
$\begin{array}{l}\text { Grouping of } \\
\text { rheumatic disorder }\end{array}$ & Reporting rheumatic condition code \\
\hline $\begin{array}{l}\text { Arthritis } \\
\text { Unspecified }\end{array}$ & $\begin{array}{l}\text { Diffuse diseases of connective tissue, 710; arthropathy associated with infections (excluding rheumatic } \\
\text { fever), 711; crystal arthropathies (including gouty arthritis, chondrocalcinosis), 712; arthropathy } \\
\text { associated with other disorders classified elsewhere, 713; osteoarthritis and allied disorders (excluding } \\
\text { osteoarthrosis of the spine (721)), 715; other and unspecified arthropathies, 716 }\end{array}$ \\
Rheumatoid arthritis & $\begin{array}{l}\text { Rheumatoid arthritis and other inflammatory polyarthropathies, } 714 \\
\text { Back or neck }\end{array}$ \\
$\begin{array}{l}\text { Ankylosing spondylitis and other inflammatory arthropathies, 720; spondylosis and allied disorders, 721; } \\
\text { intervertebral disc disorders, 722; other disorders of cervical region, 723; other and unspecified disorders } \\
\text { of back, 724; curvature of spine (excluding congenital), 737 }\end{array}$ \\
$\begin{array}{l}\text { Polymyalgia rheumatica, 725; peripheral enthesopathies and allied syndromes, 726; other disorders of } \\
\text { synovium, tendon, and bursa, 727; disorders of muscle, ligament, and fascia, 728; other disorders of soft } \\
\text { tissue (rheumatism unspecified, fibrositis, pain in limb), 729 }\end{array}$ \\
$\begin{array}{l}\text { Internal derangement of knee, 717; other derangement of joint (articular cartilage disorder, loose body in } \\
\text { joint), 718; other and unspecified disorder of joint (effusion of joint, pain in joint), 719; osteomyelitis, } \\
\text { periostitis, and other infections affecting bone, 730; osteitis deformans and osteopathies associated with } \\
\text { other disorders, 731; osteochondropathies, 732; other disorders of bone and cartilage (osteoporosis), 733; } \\
\text { flat feet, 734; acquired deformities of toe, 735; other acquired deformities of limbs, 736; other acquired } \\
\text { deformity, 738 }\end{array}$ \\
\hline
\end{tabular}

